\title{
The Outcomes of 150 Consecutive Patients with Digital Nerve Injuries Treated in a Single Center
}

\author{
Sladana Z. ANĐELKOVIĆ ${ }^{1}$, Aleksandar R. LESIC ${ }^{1}$, Marko Ž. BUMBASIREVIC ${ }^{1}$, Lukas G. RASULIC ${ }^{2}$ \\ ${ }^{1}$ Clinical Center of Serbia, Orthopedic and Traumatology Clinic, Belgrade, Serbia \\ ${ }^{2}$ Belgrade University, School of Medicine, Clinical Center of Serbia, Clinic of Neurosurgery, Belgrade, Serbia
}

\section{ABSTRACT}

AIM: The surgical management of injured digital nerves is a common part of hand trauma surgery. Despite improvements in the surgical techniques and suture material, the final outcomes of peripheral nerve repair can still be disappointing. This study investigates the outcomes following the surgical treatment of traumatic digital nerve lesions of the hand.

MATERIAL and METHODS: 150 consecutive patients with acutely digital nerve injuries were treated through by primary repair in our Unit between January 2005 and December 2009. 126 were male, 24 female (male/female ratio of 5.25:1), with an age range of 16-70 years, and a mean follow-up of 30 months. All 150 patients underwent primary epineural suture within 48 hours of their injury. Sensory recovery was assessed using the Medical Research Council scale (MRC). Sensibility testing was performed after a minimum of 12 months. Disabilities of the Arm, Shoulder and Hand scores (DASH) were used to evaluate the functional outcomes.

RESULTS: Eighteen patients (9.33\%) had excellent sensibility with two-point discrimination test (S2PD) of $\leq 7 \mathrm{~mm}$ (S4). Forty-one patients (21.24\%) achieved good sensibility (S2PD $\leq 15 \mathrm{~mm}, \mathrm{~S} 3+), 76(39.38 \%)$ achieved S3, 55 (28.50\%) had poor sensibility (S2 and S1), and two patients had no sensibility (S0). The mean functional DASH score was 9.0 in our group of patients.

CONCLUSION: There was a significant correlation between patient age, mechanism of injury and nerve recovery, with younger patients and patients with narrow zone of injury achieving better sensory recoveries.

KEYWORDS: Digital nerve, Nerve repair, Hand injury

\section{INTRODUCTION}

$\mathrm{N}$ erve injuries are common in trauma surgery and appear more frequently if the upper extremity is affected. Peripheral nerve injuries are common and occur in an estimated $2-3 \%$ of patients admitted to trauma centers (11). If plexus and root injuries are also include, the incidence is about $5 \%$ (11). The incidence has continued to rise over recent years mostly in relation to industrial and traffic accidents (14). Radial nerve injuries are the most commonly reported in the upper limb, followed by ulnar and median nerves (17). Lower limb peripheral nerve injuries are less common (15). The most common complete or partial transection injury is to the digital nerves (incidence $6.2 / 100,000$ inhabitants/year) (3), which account for $46.3 \%$ of upper extremity nerve injuries (19). These nerve injuries are rarely isolated, and are often combined with injuries to their adjacent structures (including tendons, arteries and bones).

The current surgical treatments for peripheral nerve injury often fail to provide a satisfactory functional recovery (8). It is well known that minor trauma can lead to severe disability. The aim of any treatment is to achieve as full a functional recovery as possible in order to allow the individual to return to their previous job and everyday life activities.

Diagnostic and treatment of peripheral nerve injuries still represent a challenge. Nerve conduction testing has little value in the acute hand injury setting, and accurate diagnoses were made through a combination of the clinical examination and from the intraoperative evaluation. Ultrasound can be used as a diagnostic tool in peripheral nerve injury. In the acute stage, 
determination of complete or incomplete lesion, the presence of hematoma and foreign body may be demonstrated by using ultrasonography (2). There is no single successful treatment algorithm and unfortunately, results of nerve repair to date have been no better than fair, with only $50 \%$ of patients regain satisfactory outcomes of useful function (8).

Surgical techniques have reached an optimal technical refinement and new concepts are needed to further increase the results from nerve repair, as various types of tissue engineering combined by bioartificial conduits and gene therapy (10).

\section{- MATERIAL and METHODS}

150 consecutive patients with acutely digital nerve lacerations were treated through by primary repair in our Unit between January 2005 and December 2009. All the nerve injuries were located in the distal palm or in the digits. The series consisted of 126 male patients and 24 female patients, aged between 16 and 70 years (mean, 34.34 years). All patients had unilateral injuries, 63 involving the left hand and 87 involving the right hand; 96 patients had injured their dominant hands. Sharpcut injuries accounted for $90.66 \%$ (glass, knife, metal), while the remaining $9.34 \%$ were caused by circular saws and other types of machinery. Patients with associated bone or joint injuries, and those requiring revascularization or replantation were excluded from this study. Patients with associated flexor tendon injuries were not excluded.

Patients were operated within 48 hours of their injuries. Repairs were performed under arm tourniquet with regional anesthesia (usually an axillary nerve block). Prophylactic intravenous cephalosporin antibiotics were routinely given prior to surgical incision, and antibiotics were continued for ten days post-operatively. Tourniquets were released prior to skin closure to assist with hemostasis.

In general, wounds were explored through Bruner zigzag incisions. The palmar aspect of the wrist was opened to retrieve retracted flexor tendons as required. Tendons were repaired using 3-0 or 4-0 Ticron coated, braided polyester with a double knot; the thickness of the suture depending on the size of the tendon. Injured digital nerves were isolated and then repaired with 8-0 or 9-0 monofilament nylon under loupe magnification (Figure 1A, B), using an epineural suture. No patient in our series required neural grafting. Hands were initially immobilized in dorsal splints with $30^{\circ}$ of flexion at the wrist, $60^{\circ}$ of flexion at the metacarpophalangeal (MCP) joints and $0^{\circ}$ at the IP joints (Figure 2A, B). These splints were regularly removed for wound inspection.

Rehabilitation was started on the first postoperative day with active flexion and active extension within the splint, supervised by a Hand therapist. The mobilization program consisted of active flexion of the interphalangeal joints from their resting position to $30^{\circ}$, followed by gentle slow extension to $0^{\circ}$. These exercises were repeated slowly ten times with three sessions on the first day, and then gradually increased. After four weeks the dorsal splints were changed to neutral wrist splints for two further weeks. Passive stretching was allowed six weeks after surgery. If a patient had an isolated digital nerve injury then splints were removed completely after three weeks.
Final assessment was performed after a minimum of twelve months. We record epidemiological data as factors as sex, age, etiology, dominance, number of injured digits and level of injury. Sensory recovery was measured using the Medical Research Council scale (MRC) (Table I).

This is a six level (SO-S4) evaluation assessing deep cutaneous pain, the presence or absence of hyperesthesia, tactile sensibility and static two-point discrimination. Functional outcomes were assessed using the validated Disabilities of the Arm, Shoulder and Hand (DASH) questionnaire. A higher score on the DASH reflects a greater disability.

Average follow-up was 30 months (range 12 months to 5 years). Data were statistically analyzed using the SPSS Statistics 17.0 package.

\section{RESULTS}

150 patients underwent surgical repair of their digital nerve injuries. 120 patients had single digit nerve injuries, and 30 patients had multiply injured digits. Index fingers were the most commonly involved, accounting for 71 of the 193 injured digits. 84 patients $(56 \%)$ had associated digital artery injuries. Digital artery reconstruction was only possible in $22 \%$ of these cases: however all injured digits viable distally in spite of this. There were 127 associated tendon injuries requiring surgical repair. There were no wound healing problems. Patient characteristics, and types and mechanisms of injury are summarized (Table II).

After a mean follow-up of 30 months (range 12 months do five years), almost $31 \%$ of patients had regained normal or near normal sensation (Table III)

Eighteen patients (9.33\%) had excellent sensibility with S2PD of $\leq 6 \mathrm{~mm}$ (S4). Forty-one patients (21.24\%) achieved good sensibility (S2PD $\leq 15 \mathrm{~mm}, \mathrm{~S} 3+$ ), seventy-six (39.38\%) had S3, fifty-five (28.50\%) had poor sensibility (S2 and $\mathrm{S} 1$ ), and three patients had no sensibility (SO). The mean functional DASH scores were 9.0 in our group of patients. Functional outcomes were significantly better in those patient with isolated digital nerve injuries (mean DASH scores of 1.2), when compared to those patients with associated tendon injuries (means DASH scores of 16.8).

The conducted Spearman correlation confirmed significant association between the stage of the Medical Research Council scale and individuals' age $(\rho=-0.857 ; p<0.001)$, strongly suggesting that younger individuals will achieve better recovery. The applied tests (ANOVA), however revealed the low level of stage discrimination according to the age between the first two stages i.e. SO and S1, as well as between the last two stages i.e. S3+ and S4 ( $p>0.05)$ while mutual distinction between all other stages were statistically significant $(p<0.001)$.

The narrow zone of injury was statistically more frequent in our sample $\left(X^{2}=127.715 ; p<0.001\right)$, and according to our research the younger individuals were more prone to it $\rho=0.259$; $\mathrm{p}<0.001$ ). 
The applied Mann-Whitney $U$ Test demonstrated the statistically significant influence of mechanism of injury to patient recovery $(Z=-4.254 ; p<0.001)$ reveling higher mean scores of the Medical Research Council scale in the group of patients with narrow injury zone.

\section{DISCUSSION}

How does the loss of digital sensibility truly affect manual dexterity? Schenker et al. investigated prevision grip function during lifting tasks in patients after replantation and after single digital nerve lesions, also in healthy subjects with digital

Table I: Medical Research Council Scale

So Absence of sensibility in the autonomous area

S1 Recovery of deep cutaneous pain sensibility within the autonomous area of the nerve

S2 Return of some degree of superficial cutaneous pain and tactile sensibility within the autonomous area of the nerve

S3

Return of superficial cutaneous pain and tactile sensibility throughout the autonomous area, with disappearance of any previous overresponse

S3+

Return of sensibility as in S3; in addition, there is some recovery of 2-point discrimination within the autonomous area (7-15 mm)

S4 Complete recovery (2-point discrimination, 2-6 mm)
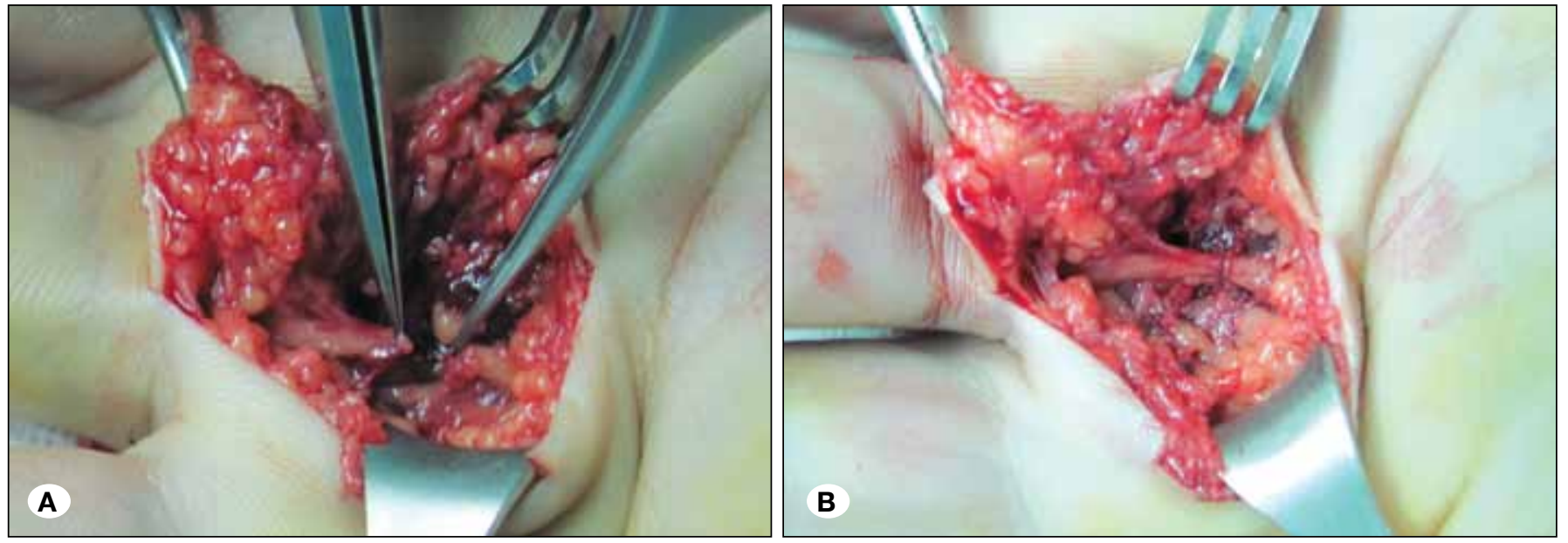

Figure 1: A) Injured digital nerve. B) Digital nerve suture.
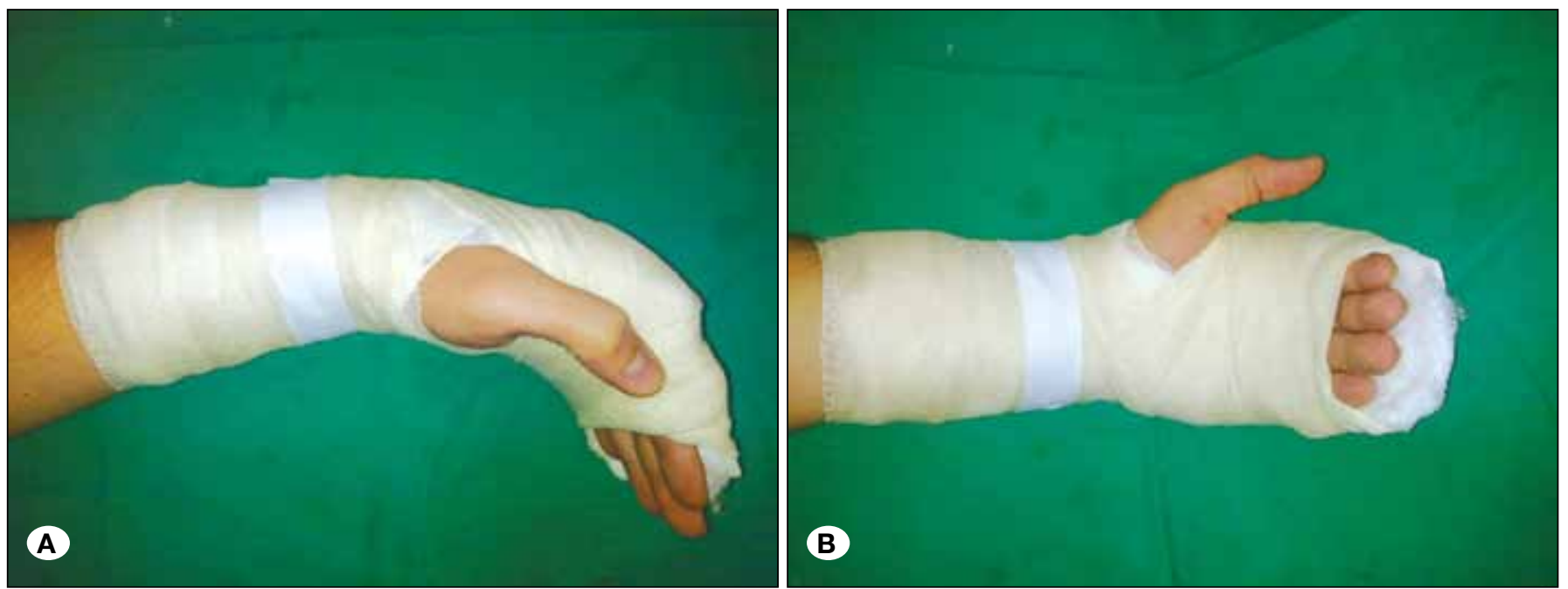

Figure 2A, B: Dorsal splint after suture. 
block anesthesia. They founded that all subjects were able to successfully lift test objects with parallel and vertical grip surfaces and they increased grip forces when lifting heavier objects. However, the grip forces used were significantly higher (16). They compensate loss of sensibility with high grips forces and showed misalignments of the fingertips on the

Table II: Demographic Characteristics of the Patients

\section{Patients Demographics}

Number of patients*

\begin{tabular}{ll}
\hline Total & 150 \\
\hline Gender & 126 \\
\hline Male & 24 \\
\hline Female & 34.34 \\
\hline Mean age (years) & 96 \\
\hline Injured Dominant Hand & \\
\hline Injured Hand & 87 \\
\hline Right & 63 \\
\hline Left
\end{tabular}

\begin{tabular}{lc}
\hline Cause of Injury & \\
\hline Knife & 65 \\
\hline Glass & 43 \\
\hline Metal cut & 28 \\
\hline Circular saw & 9 \\
\hline Others & 5 \\
\hline No of Digits with Tendon Injury & 127 \\
\hline No of Injured Digits & 120 \\
\hline One & 21 \\
\hline Two & 5 \\
\hline Three & 4 \\
\hline Four & 0
\end{tabular}

Injured Digit

\begin{tabular}{ll}
\hline Thumb & 51 \\
\hline Index finger & 71 \\
\hline Middle finger & 30 \\
\hline Ring finger & 22 \\
\hline Little finger & 19 \\
\hline Injured Digital Arteries & 84 \\
\hline Sutured digital arteries & 19 \\
\hline
\end{tabular}

*The value represents the number of patients. grasp surfaces. The contralateral hand tried to minimize the abnormal grasp patterns of the injured hand (16). The digital nerves also provide protection from thermal burns, frostbite and others injuries.

Our series found that isolated nerve injuries were uncommon and occurred in only eight of our patients (5.33\%). This is similar to the published literature were a reported $2.7 \%$ of patients suffer isolated nerve injuries (19), while $48 \%-82 \%$ of patients with flexor tendon lacerations have associated digital nerve injuries $(6,12,13,18)$.

The demographics of our series were similar to other published data. Peripheral nerve injuries were more common in young men, with a 5.25-fold male prevalence, and occurred at a mean age of 34.3 years. Other series found that men suffer $70-75 \%$ of these injuries $(3,5)$, at mean ages of 31 (5), and 38 years (9).

Knife injuries were the leading cause of peripheral nerve injuries $(43.33 \%)$ in our study, with glass $(28.66 \%)$, and metal cuts (18.66\%) being the next common causes. Other series have described peripheral nerve injuries resulting from glass lacerations in $73 \%$ and knives in $27 \%$ (19) while others found that $72 \%$ of peripheral nerve injuries were the result of domestic glass or knife accidents (7).

The most common injured digits were the index finger $(36.79 \%)$ and the thumb $(26.42 \%)$, contrasting with other published data which found that the fourth digit was affected in $30 \%$ and the index finger in $26 \%$ (19).

We must employed postoperative tendon motion exercise in those cases were flexor tendon was cut and repaired, because of need to preventing adhesion formation and provide better outcome. Question is what we need when digital nerve injury is isolated. Some have suggested that there is no need to splint nerve repairs (20), however our rationale was based on a cadaveric study which found that the tensile failure strength of intact digital nerves is $6 \mathrm{~N}$, with repaired nerves failing under $1-2 \mathrm{~N}$, and more importantly that maximal metacarpophalangeal joint hyperextension results in $4 \mathrm{~N}$ of digital nerve tension (4). Therefore, we believed that some form of protective splinting is necessary after digital nerve repairing.

Digital nerve lesions as pure sensitive nerves are ideal for clinical outcome studies, but only a few data have been

Table III: Results of Evaluation of Sensibility

\begin{tabular}{|c|c|}
\hline MRC scale & $n=193^{\star}(\%)$ \\
\hline So & 3 (1.55\%) \\
\hline S1 & 18 (9.33\%) \\
\hline $\mathrm{S} 2$ & 37 (19.17\%) \\
\hline S3 & 76 (39.38\%) \\
\hline S3+ & 41 (21.24\%) \\
\hline S4 & 18 (9.33\%) \\
\hline
\end{tabular}

*The value represents the number of digital nerves. 
published so far (9). Another retrospective study looking at the outcomes of digital replantations and revascularization found poor resultant sensibility in affected thumbs and digits (1), though one should appreciate that the associated soft tissue and bony injuries would adversely affected these final outcomes.

When we evaluated the results of sensibility recovery, we found that most of the patients reached S3 (39.38\%) and S3+ $(21.24 \%)$. Only three patients reported poor sensibility (SO). We found that our younger patients had better functional outcomes similar to other series $(5,14)$, with all those achieving an S4 recovery being younger than 24 years; this is probably due to an increased potential for regeneration and central nervous elasticity in younger patients.

We found significant influence of mechanism of injury to patient recovery. Also we noticed that the narrow zone of injury give rise to better results. We have to mention that in our series majority of patients are sustained injury whit glass and knives. As well the younger patients had the narrow zone of injury which may has influence on statistic results.

Mean DASH scores in our series were 9.0 after twelve months. Results of these hand and upper-extremity questionnaire we didn't founded in the available studies of digital nerves lacerations. DASH scores were better in the patients with an isolated digital nerve injury (1.2), while those suffering flexor tendon lacerations in whom DASH scores were a mean of 16.8 .

Most patients with digital nerve repairs made good and excellent recoveries. There was a significant correlation between patient age and nerve recovery, with younger patients achieving better sensory recoveries. The microsurgical technique has been much improved but other investigations are requires to improve results. Basic nerve research contributes to better understanding of nerve biology, regeneration and potential for use grow factors and gene therapy.

\section{REFERENCES}

1. Blomgren I, Blomqvist G, Ejeskär A, Fogdestam I, Volkman R, Edshage S: Hand function after replantation or revascularization of upper extremity injuries. Scand J Plast Reconstr Surg 22: 93-101, 1988

2. Cokluk C, Aydin K: Ultrasound examination in the surgical treatment for upper extremity peripheral nerve injuries: Part I. Turk Neurosurg 17: 277-282, 2007

3. Dahlin LB: Nerve injuries. Current Orthopaedics 22:9-16, 2008

4. Goldberg SH, Jobin CM, Hayes AG, Gardner T, Rosenwasser MP, Strauch RJ: Biomechanics and histology of intact and repaired digital nerves: An in vitro study. J Hand Surg 32(4):474-482, 2007

5. Guerra WK, Baldauf J, Schroeder HW: Long-term results after microsurgical repair of traumatic nerve lesions of the upper extremities. Zentralbl Neurochir 68(4):195-199, 2007
6. Hung LK, Pang KW, Yeung PLC, Cheung L, Wong JMW, Chan $P$ : Active mobilisation after flexor tendon repair: Comparison of results following injuries in zone 2 and other zones. J Orthop Surg 13(2):158-163, 2005

7. Kumar S, Hassouna H, Penematsa S: Clinical and userfriendly classification of traumatic digital nerve injuries of hand. Acta Ortop Trauma Sur 127(7):527-530, 2007

8. Lee SK, Wolf SW: Peripheral nerve injury and repair. J Am Acad Orthop Surg 8:243-252, 2000

9. Lohmeyer JA, Siemers F, Machens HG, Mailänder P: The clinical use of artificial nerve conduits for digital nerve repair: A prospective cohort study and literature review. J Reconstr Microsurg 25:55-61, 2009

10. Lundborg G: A 25-year perspective of peripheral nerve surgery: Evolving neuroscientific concepts and clinical significance. J Hand Surg 25A: 391-414, 2000

11. Noble J, Munro CA, Prasad VS, Midha R: Analysis of upper and lower extremity peripheral nerve injuries in a population of patients with multiple injuries. J Trauma 45:116-122, 1998

12. Nuley JA, Levin LS, Devito D, Goldner RD, Urbaniak JR: Direct end-to-end repair of flexor policies long us tendon lacerations. J Hand Surg 17(1):118-121, 1992

13. Ozturk K, Orhun E, Polatkan O, Polatkan S: Long-term results of early primary repair of flexor policies long us tendon injuries. Acta Orthop Traumatol Turc 38(1):50-53, 2004

14. Portincasa A, Gozzo G, Parisi D, Aninacontini L, Campanale A, Basso G, Maiorella A: Microsurgical treatment of injury to peripheral nerves in upper and lower limbs: A critical review of the last eight years. Microsurgery 27:455-462, 2007

15. Robinson LR: Traumatic injury to peripheral nerves. Jpn J Rehabil Med 42:89-98, 2005

16. Schenker M, Burstedt MK, Wiberg M, Johansson RS: Precision grip function after hand replantation and digital nerve injury. $J$ Plast Reconstr Aesthet Surg 59(7):706-716, 2006

17. Selecki BR, Ring IT, Simpson DA, Vanderfield GK, Sewell MF: Trauma to the central and peripheral nervous systems: Part II, a statistical profile of surgical treatment in New South Wales 1977. Aust NZJ Surg 52: 111-116, 1982

18. Su BW, Solomons M, Barrow A, Senoge ME, Gilberti M, Lubbers L, Diao E, Quitkin HM, Rosenwasser MP: Device for tone -II flexor tendon repair. A multicenter, randomized, blinded, clinical trial. J Bone Joint Surg Am 87(5):923-935, 2005

19. Tuncali D, Toksoy K, Baser NT, Terzioglu A, Aslan G: Upper extremity nerve injuries: The significance of soft tissue associations. Neuroanatomy 3:15-17, 2004

20. Vipond N, Tylor W, Rider M: Postoperative splinting for isolated digital nerve injuries in the hand. J Hand Ther 20(3):222-230, 2007 